\title{
Black soyabean seed coat extract regulates iron metabolism by inhibiting the expression of hepcidin
}

\author{
Mingdao $\mathrm{Mu}^{1,2}$, Aimin $\mathrm{Wu}^{2}$, Peng $\mathrm{An}^{1,2}$, Xiaoli $\mathrm{Du}^{2}$, Qian $\mathrm{Wu}^{1,2}$, Xiaoyun $\mathrm{Shen}^{2}$ and Fudi Wang ${ }^{2,3 *}$ \\ ${ }^{1}$ Key Laboratory of Nutrition and Metabolism, Institute for Nutritional Sciences, Shanghai Institutes for Biological \\ Sciences, Chinese Academy of Sciences, Graduate School of the Chinese Academy of Sciences, Shanghai 200031, \\ People's Republic of China \\ ${ }^{2}$ Department of Nutrition, Center for Nutrition and Health, Institute of Nutrition and Food Safety, School of Public Health, \\ School of Medicine, Zhejiang University, Hangzhou 310058, People's Republic of China \\ ${ }^{3}$ Collaborative Innovation Center for Diagnosis and Treatment of Infectious Diseases, Zhejiang University, \\ Hangzhou 310058, People's Republic of China
}

(Submitted 10 September 2013 - Final revision received 29 October 2013 - Accepted 5 November 2013 - First published online 6 January 2014)

\section{Abstract}

Hepcidin, a key regulator of Fe homeostasis, is an ideal drug target for treating patients with Fe disorders such as haemochromatosis, anaemia of chronic inflammation and Fe-deficiency anaemia. However, whether (and how) traditional Chinese black foods (e.g. black soyabeans) target hepcidin and improve Fe-deficiency anaemia remains unclear. Herein, we report that black soyabean seed coat extract (BSSCE) can potently inhibit the in vitro and in vivo expression of hepcidin. In the present study, in cells treated with $200 \mu \mathrm{g} / \mathrm{ml} \mathrm{BSSCE}$, hepcidin expression was found to be reduced to only $6 \%$ of the control levels $(P<0 \cdot 01)$. An AIN-76A diet containing $2 \%$ BSSCE was fed to 8-week-old male C57BL/ 6 mice for $0,1,7,15$ or $30 \mathrm{~d}$; importantly, compared with the day 0 group, the day 7 group exhibited nearly a $50 \%$ decrease in hepatic hepcidin expression $(P<0 \cdot 01)$, a $35 \%$ decrease in splenic Fe concentrations $(P<0 \cdot 05)$ and a $135 \%$ increase in serum Fe concentrations $(P<0.05)$. Mechanistically, the effect of BSSCE on hepcidin expression was mediated via a reduction in the phosphorylation levels of mothers against decapentaplegic homolog proteins (Smad)1/5/8. Consequently, the mice in the day 30 group exhibited large increases in erythrocyte counts $(111 \% v$. day $0, P<0 \cdot 01)$, Hb concentrations $(109 \%, P<0 \cdot 01)$ and haematocrit values $(108 \%, P<0 \cdot 01)$. In conclusion, these results indicate that black soyabean extract regulates Fe metabolism by inhibiting the expression of hepcidin. This finding can be used to optimise the intervention of patients with hepcidin-related diseases, including Fe-deficiency anaemia.

\section{Key words: Black soyabeans: Hepcidin: Iron metabolism: Nutrition}

$\mathrm{Fe}$ is an essential trace element in many physiological processes, and systemic Fe homeostasis plays an essential role in metabolism ${ }^{(1)}$. Hepcidin is a peptide hormone that is produced and excreted by the liver. Hepcidin is encoded by the hepcidin antimicrobial peptide (HAMP) gene and regulates systemic Fe homeostasis by binding to ferroportin, the only known mammalian non-haeme Fe export protein. This binding leads to the degradation of ferroportin, thereby controlling Fe transport and ultimately regulating several processes, including Fe absorption in the intestine, Fe mobilisation from the liver and Fe recycling from the macrophages ${ }^{(2-4)}$.

The expression of hepatic $H A M P$ is regulated by dietary $\mathrm{Fe}$, inflammation and erythropoietin activity, all of which primarily involve the bone morphogenetic protein (BMP) mothers against decapentaplegic homolog protein (SMAD) and Janus kinase-signal transducer and activator of transcription signalling pathways ${ }^{(5-7)}$. Impaired hepcidin secretion causes Fe overload, and hepcidin overexpression is associated with many diseases, including anaemia of chronic disease and Fe-deficiency anaemia ${ }^{(4)}$. Recent studies $^{(8,9)}$ have focused on the identification of hepcidin antagonists. For example, dorsomorphin and its derivatives (which are inhibitors of the BMP/SMAD pathway) ${ }^{(10,11)}$ and an IL-6 antagonist ${ }^{(12)}$ have a curative effect in a mouse model of chronic inflammation-associated anaemia. However, further studies are needed to test the safety of these compounds in clinical applications. The ultimate therapeutic goal is to treat Fe metabolism disorders using functionally active foods that target hepcidin and/or its regulatory proteins $^{(13,14)}$.

Abbreviations: BMP, bone morphogenetic protein; BSSCE, black soyabean seed coat extract; ERK, extracellular signal-regulated kinase; HAMP, hepcidin antimicrobial peptide; SMAD, mothers against decapentaplegic homolog proteins; STAT, signal transducer and activator of transcription.

*Corresponding author: F. Wang, email fwang@zju.edu.cn; fudiwang.lab@gmail.com 
Since ancient times, many empirical dietary therapies for treating a wide variety of diseases have emerged in both traditional Chinese medicine and dietary culture ${ }^{(15,16)}$. Food therapies for treating anaemia are abundant in the traditional Chinese pharmacopoeia, particularly foods that have unique colours $^{(17)}$. However, because it is generally more difficult to absorb Fe from plant matter than haeme Fe from animal sources $^{(18)}$, we hypothesised that plant foods that treat anaemia might actually function by regulating hepcidin expression rather than serving as a significant source of dietary Fe. Traditionally, Chinese foods that are black in colour are believed to contain more nutrients and to induce erythropoiesis; in China, these foods are called 'black foods'. In the present study, to investigate their function and molecular mechanisms, we obtained extracts of several black foods, including Glycine max (black soyabean, also known as Hei Dou), Auricularia auricula-judae (black fungus, Hei $\mathrm{Mu}$ Er), Sesamum indicum seeds (black sesame seeds, Hei Zhi Ma) and Diospyros lotus (date plum or persimmon, Hei Zao), and tested their effects on hepcidin expression. We found that black soyabean extract regulates Fe metabolism by inhibiting hepcidin expression both in vitro and in vivo.

\section{Experimental methods}

\section{Preparation of experimental materials}

Standard water extracts (10:1) of four foods, including G. max, A. auricula-judae, S. indicum seeds and D. lotus, were purchased from Hao Yang Biotech Company Limited for the first screening stage (Table 1). High-concentration extracts of black soyabean coat (containing at least 30\% anthocyanins) were purchased from JF-Natural Company Limited. These extracts were dissolved in sterile PBS to $50 \mathrm{mg} / \mathrm{ml}$. Recombinant human BMP6 and recombinant human IL-6 were purchased from R\&D Systems. Each aqueous extract was filtered through a $0.22 \mu \mathrm{m}$ membrane (Millipore) before being added to the cultured cells.

\section{Cell-culture assays}

HepG2 cells (a human hepatocyte cell line) and human embryonic kidney (HEK293) cells were obtained from the Cell Bank of Shanghai Institutes for Biological Sciences,

Table 1. Iron concentrations and functional components of food extracts that were used in the cell line screening experiment

(Mean values and standard deviations, $n 3$ )

\begin{tabular}{lccl}
\hline & \multicolumn{2}{c}{$\begin{array}{c}\text { Fe concentration } \\
\text { (ppm)* }\end{array}$} & \\
\cline { 2 - 3 } Functional food name & Mean & SD & Functional part \\
\hline Glycine max (black soyabean) & 1.04 & 0.02 & Coat \\
Sesamum indicum & 1.54 & 0.06 & Seed \\
Diospyros lotus & 0.09 & 0.11 & Fruit \\
Auricularia auricula-judae & 1.29 & 0.03 & Sporocarp \\
\hline
\end{tabular}

ppm, Parts per million.

*Total Fe concentration was measured using inductively coupled plasma MS.
CAS, and were cultured in Dulbecco's modified Eagle's medium (Gibco) supplemented with 10\% heat-inactivated fetal bovine serum (Gibco) and $1 \times$ penicillin-streptomycin (Gibco); the cells were incubated at $37^{\circ} \mathrm{C}$ in $5 \% \mathrm{CO}_{2}$. The Cell Counting Kit-8 (Dojindo Laboratories) was used in accordance with the manufacturer's instructions to measure black soyabean seed coat extract (BSSCE) cytotoxicity. Methods reported by Poli et al. ${ }^{(19)}$ were used to assess the phosphorylation levels of Smad1/5/8, extracellular signalregulated kinase (Erk)1/2 and signal transducer and activator of transcription (Stat)3. For screening, HepG2 cells were treated for $12 \mathrm{~h}$ with $200 \mu \mathrm{g} / \mathrm{ml}$ of each functional food extract. To test the inhibitory effect of BSSCE on BMP6- and IL-6induced HAMP expression, the cell-culture medium was pretreated with BSSCE for $30 \mathrm{~min}$ before stimulation with

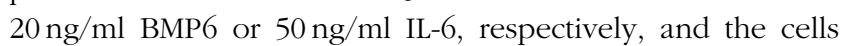
were then incubated for $12 \mathrm{~h}^{(9,19,20)}$.

\section{Luciferase reporter assay}

In accordance with the manufacturer's instructions (Fugene HD Transfection Reagent; Promega), we plated HEK293 cells in twenty-four-well plates at least $1 \mathrm{~d}$ before transfection, and the medium was replaced when the cells reached approximately $60 \%$ confluence. The HAMP promoter luciferase reporter gene construct pGL3-HAMP was generated, containing $2.7 \mathrm{~kb}$ of the $5^{\prime}$-flanking genomic region of the human HAMP gene plus the $5^{\prime}$-UTR (untranslated region, from -2700 to $+71 \mathrm{bp}$ ), and the pGL3-HAMP and the control Renilla reporter were co-transfected ${ }^{(21)}$. After $24 \mathrm{~h}$, the cells were subjected to a variety of treatments and then lysed in $150 \mu \mathrm{l}$ of luciferase cell-culture lysis reagent (Promega). The cell lysates were analysed for luciferase activity using a dual-luciferase reporter assay system (Promega). Relative luciferase activity was calculated as the ratio of firefly: Renilla luciferase. All the experiments were carried out at least three times ${ }^{(22)}$.

\section{Animal experiments}

Male C57BL/6 mice (SLRC Laboratory Animal Company Limited) aged 8 weeks were maintained under pathogenfree conditions and given free access to an AIN-76A standard diet (Fe concentration: $57 \cdot 23$ (SD 1.24) parts per million) ${ }^{(23)}$ or a BSSCE-containing diet (Fe concentration: 58.36 (SD 2.12) parts per million). The experimental mice were randomly assigned to the various groups and fed a diet containing $2.0 \%(\mathrm{w} / \mathrm{w})$ dried BSSCE (see Fig. 5(A)). After BSSCE treatment for $0,1,7,15$ or $30 \mathrm{~d}$, the mice were killed under anaesthesia ( $5 \%$ chloral hydrate, $10 \mathrm{ml} / \mathrm{g}$ body weight by intraperitoneal injection). Whole blood was collected, and the livers and spleens were harvested for further analysis. The protocols for measuring serum and tissue Fe concentrations have been described previously ${ }^{(3)}$; each group contained six to eight mice. All the animal experiments were approved by the Institutional Animal Care and Use Committee of Shanghai Institutes for Biological Sciences, Chinese 
Academy of Sciences, and Animal Care and Use Committee of Zhejiang University.

\section{RNA extraction and quantitative PCR analysis of mRNA transcripts}

RNA was extracted as described previously ${ }^{(3)}$ using the SuperfecTRI RNA Isolation Reagent (Pufei). The following primer sequences $\left(5^{\prime}-3^{\prime}\right)$ were used for quantitative PCR: HAMP: forward CAGCTGGATGCCCATGTTC/reverse CAGCAGCCGCAGCAGAA; ACTIN: forward CACGGCATCGTCACCAACT/reverse CACGCAGCTCATTGTAGAAGGT; mouse Hamp1: forward GCACCACCTATCTCCATCAACA/reverse TTCTTCCCCGTGCAAAGG; mouse Actb ( $\beta$-actin): forward AAATCGTGCGTGACATCAAAGA/reverse GCCATCTCCTGCTCGAAGTC; mouse inhibitor of DNA binding 1 (Id1): forward CGCAGCCACCGGACTCT/reverse AACCCССТCСССAAAGTC; mouse Вmpб: forward ATGGCAGGACTGGATCATTGC/reverse CCATCACAGTAGTTGGCAGCG.

\section{Western blot analysis}

The cells were lysed and analysed as described previously ${ }^{(3)}$. The following primary antibodies were used: rabbit antipSmad1/5/8 (1:1000; Cell Signaling Technology, no. 9511s); rabbit anti-Smad1 (1:1000; Cell Signaling Technology, no. 9743s); rabbit anti-pStat3 (1:1000; Cell Signaling Technology, no. 9131s); rabbit anti-Stat3 (1:1000; Cell Signaling Technology, no. 9132s); rabbit anti-pErk1/2 (1:1000; Cell Signaling Technology, no. 4376); rabbit anti-Erk1/2 (1:1000; Cell Signaling Technology, no. 4695); mouse anti- $\beta$-actin (1:2000; Sigma-Aldrich, no. A5316).

\section{Inductively coupled plasma MS measurement of total iron concentrations}

An Agilent 7500cx inductively coupled plasma MS system equipped with a G3160B I-AS integrated autosampler was used to measure $\mathrm{Fe}$ concentrations in the functional food extracts that were used for cell treatment and added to the animal diet. This procedure was carried out as described previously ${ }^{(24)}$.

\section{Statistical analysis}

Group differences were analysed using ANOVA, and Tukey's post hoc test was used to compare two specific groups. Some data were log-transformed to meet the assumption of homogeneity of variances (Bartlett's test). Where applicable, group means without a common letter differ significantly. Differences with $P<0.05$ were considered to be statistically significant.

\section{Results}

\section{Screening black foods for their effects on HAMP expression in HepG2 cells}

HepG2 cells, a human hepatocyte cell line, were used for the initial screening process. We treated cells for $12 \mathrm{~h}$ with
(A)
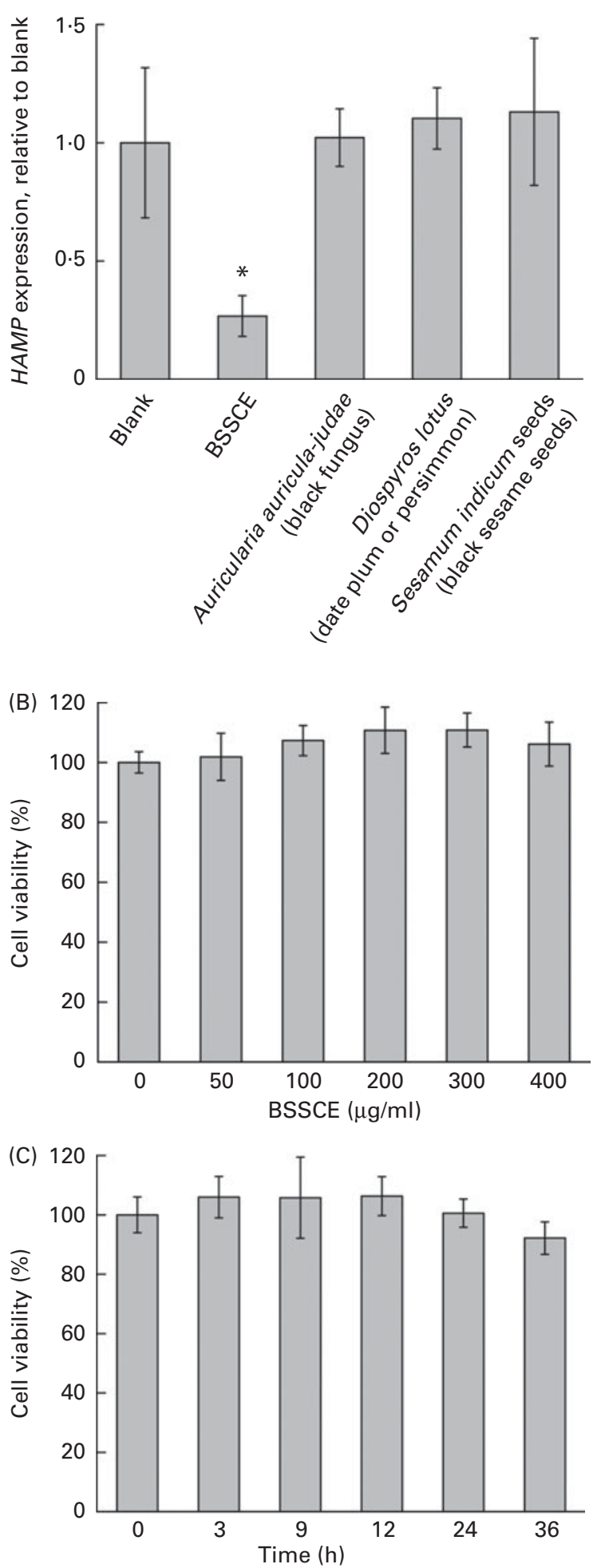

Fig. 1. Black soyabean seed coat extract (BSSCE) inhibits hepcidin expression. (A) HepG2 cells were treated for $12 \mathrm{~h}$ with $200 \mu \mathrm{g} / \mathrm{ml}$ of the standard water extract of the indicated foods, after which HAMP expression was measured. Cell viability was measured using the Cell Counting Kit-8 assay. (B) HepG2 cells were treated with the indicated concentrations of BSSCE for $12 \mathrm{~h}$. (C) HepG2 cells were treated with $200 \mu \mathrm{g} / \mathrm{ml} \mathrm{BSSCE}$ for the indicated number of hours. Values are means and standard deviations represented by vertical bars; $n 3$ experiments per group. * Mean values were significantly different from that of the blank group $(P<0.05)$. Blank, basal control cells treated with PBS. 
$200 \mu \mathrm{g} / \mathrm{ml}$ of the standard water extract of each food, including black soyabean, black fungus, black sesame seeds and date plum (persimmon). Of these four black foods that were tested, only BSSCE significantly inhibited hepcidin expression (Fig. 1). Importantly, the total $\mathrm{Fe}$ concentration of this food is relatively low (Table 1), suggesting that the effect of BSSCE on hepcidin expression is independent of the extract's Fe content. Based on this initial screening process, we used high-concentration extracts of black soyabean coat (containing at least 30\% anthocyanins) in our subsequent experiments.

\section{Black soyabean seed coat extract significantly inhibits HAMP expression in HepG2 cells}

BSSCE, which contains $\geq 30 \%$ anthocyanins, inhibited the expression of HAMP (the gene that encodes hepcidin) in the HepG2 cell line, exhibiting both dose and time dependence. At a concentration of $200 \mu \mathrm{g} / \mathrm{ml}$, BSSCE reduced HAMP expression to only $6 \%$ of the control levels (Fig. 2(A)). In the time-course experiments, HAMP expression decreased rapidly, reaching $<9 \%$ of the control levels within $12 \mathrm{~h}$ (Fig. 2(B)) Moreover, the phosphorylation levels of SMAD1/5/8, a group of transcription factors that activate the $H A M P$ gene, also decreased with similar dose and time dependence; in contrast, the phosphorylation levels of STAT3 and ERK1/2 were relatively unchanged (Fig. 2(C) and (D)).

\section{Black soyabean seed coat extract potently inhibits bone morphogenetic protein 6- and IL-6-induced HAMP expression}

BMP6 plays a key role in the regulation of hepcidin expression $^{(25)}$. In our experiments, treatment with BMP6 $(20 \mathrm{ng} / \mathrm{ml})$ triggered an almost 5.5-fold increase in $H A M P$ expression relative to the basal levels, and this increase was inhibited by treating cells with increasing concentrations of BSSCE; at a concentration of $400 \mu \mathrm{g} / \mathrm{ml}$, BSSCE reduced HAMP expression to $5.6 \%$ of the basal levels (Fig. 3(A)). BSSCE had a similar inhibitory effect on HAMP expression induced by IL-6; IL-6 (50 ng/ml) increased HAMP expression 2 -fold ${ }^{(20,26)}$, and BSSCE $(50-400 \mu \mathrm{g} / \mathrm{ml})$ inhibited IL-6induced expression; $H A M P$ expression was reduced to $2.3 \%$ of the basal levels following treatment with $400 \mu \mathrm{g} / \mathrm{ml}$ BSSCE (Fig. 3(B)). Western blot analysis also revealed that BMP6-induced phosphorylation of SMAD1/5/8 was significantly reduced by BSSCE treatment, whereas the phosphorylation levels of STAT3 and ERK1/2 remained unchanged (Fig. 3(C)). Moreover, IL-6 induced the phosphorylation of STAT3 and SMAD1/5/8, and BSSCE treatment
(A)

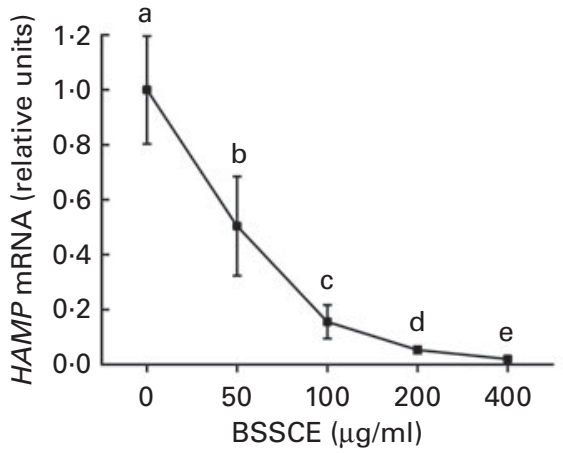

(C)

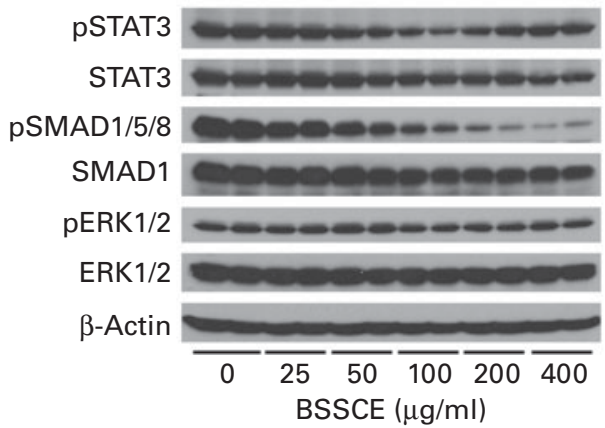

(B)

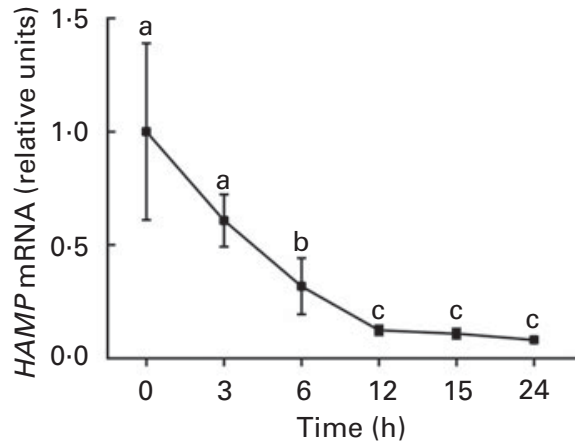

(D)

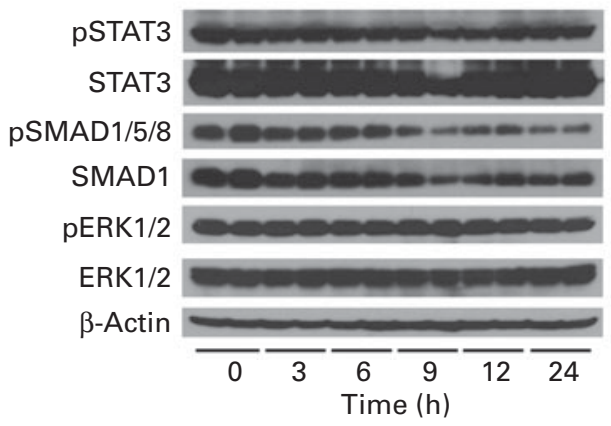

Fig. 2. Black soyabean seed coat extract (BSSCE) inhibits HAMP expression and mothers against decapentaplegic homolog protein $1 / 5 / 8$ (Smad $1 / 5 / 8)$ and signal transducer and activator of transcription 3 (Stat3) phosphorylation in HepG2 cells. (A) HAMP expression in HepG2 cells that were treated for $12 \mathrm{~h}$ with the indicated concentrations of BSSCE. (B) HAMP expression in HepG2 cells that were treated with $200 \mu \mathrm{g} / \mathrm{ml}$ BSSCE for the indicated time points. (C) Western blot analysis of phosphorylated SMAD1/5/8 (pSMAD1/5/8), phosphorylated STAT3 (pSTAT3) and phosphorylated extracellular signal-regulated kinase 1/2 (pERK1/2) in HepG2 cells after BSSCE treatment for $12 \mathrm{~h}$. (D) Western blot analysis of pSMAD1/5/8, pSTAT3 and pERK1/2 levels in HepG2 cells that were treated for the indicated time points with $200 \mu \mathrm{g} / \mathrm{ml} \mathrm{BSSCE}$. $\beta$-Actin was used as a loading control. The summary data in (A) and (B) are presented as means and standard deviations represented by vertical bars; $n 3$ replicates per group. ${ }^{\mathrm{a}, \mathrm{b}, \mathrm{c}, \mathrm{d}, \mathrm{e}}$ Mean values with unlike letters were significantly different $(P<0.05)$. 

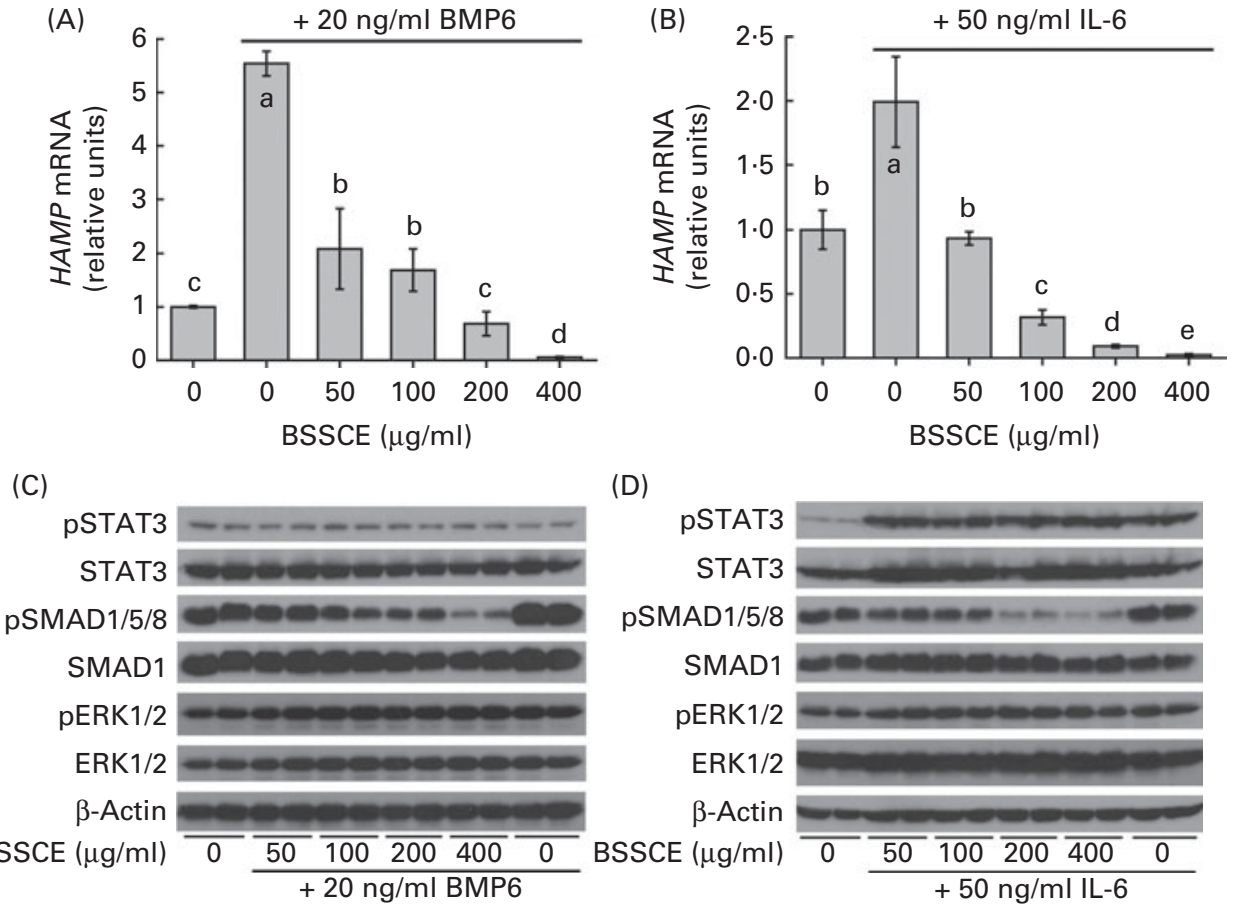

Fig. 3. Black soyabean seed coat extract (BSSCE) inhibits bone morphogenetic protein 6 (BMP6)- and IL-6-induced HAMP expression. (A and B) HAMP expression in HepG2 cells that were cultured with the indicated concentrations of BSSCE in the presence or absence of $20 \mathrm{ng} / \mathrm{ml} \mathrm{BMP6} \mathrm{(A)} \mathrm{or} 50 \mathrm{ng} / \mathrm{ml} \mathrm{IL-6}$ (B). (C-D) Western blot analysis of phosphorylated mothers against decapentaplegic homolog proteins 1/5/8 (pSMAD1/5/8), phosphorylated signal transducer and activator of transcription 3 (pSTAT3) and phosphorylated extracellular signal-regulated kinase 1/2 (pERK1/2) in HepG2 cells after BSSCE treatment in the presence or absence of $20 \mathrm{ng} / \mathrm{ml} \mathrm{BMP6} \mathrm{(c)} \mathrm{or} 50 \mathrm{ng} / \mathrm{ml} \mathrm{IL-6} \mathrm{(d)} \mathrm{for} 12 \mathrm{~h}$. $\beta$-Actin was used as a loading control. The summary data in (A) and (B) are presented as means and standard deviations represented by vertical bars; $n 3$ replicates per group. ${ }^{a, b, c, d, e}$ Mean values with unlike letters were significantly different $(P<0.05)$.

reduced the phosphorylation of SMAD1/5/8 but not of STAT3 (Fig. 3(D)).

\section{Black soyabean seed coat extract inhibits bone}

morphogenetic protein 6- and IL-6-induced HAMP expression measured using a luciferase assay

We found that treating cells for $24 \mathrm{~h}$ with BMP $6(20 \mathrm{ng} / \mathrm{ml})$ or IL-6 $(50 \mathrm{ng} / \mathrm{ml})$ increased the relative activity of a HAMP reporter luciferase assay by $2 \cdot 5$ - and $3 \cdot 5$-fold, respectively (Fig. 4). Moreover, BSSCE completely inhibited the up-regulation of BMP6-induced HAMP expression, decreasing the relative activity of the $H A M P$ promoter to $10 \%$ of the basal levels (Fig. 4(A)). Similarly, IL-6-induced HAMP expression was significantly decreased by BSSCE treatment; luciferase activity was reduced to $33 \%$ of the basal levels following treatment with $400 \mu \mathrm{g} / \mathrm{ml} \mathrm{BSSCE}$ (Fig. 4(B)).

\section{Black soyabean seed coat extract inhibits Hamp1 expression and increases iron mobilisation in mice}

We next carried out animal experiments to investigate the effect of BSSCE on Hamp1 expression in vivo. C57BL/6 mice were maintained on a diet containing $2.0 \%$ BSSCE for various time periods up to $30 \mathrm{~d}$, after which the mice were killed (Fig.5(A)). Even after $1 \mathrm{~d}$ on the BSSCE-containing diet (i.e. the day 1 group), hepatic hepcidin (Hamp1) expression in the treated mice decreased significantly to approximately $46 \%$ of that in the standard diet-fed mice (i.e. the day 0 group), and this decrease persisted up to $30 \mathrm{~d}$ of treatment (Fig. 5(B)). Interestingly, the phosphorylation of Smad1/5/8 was also reduced, particularly in the mice treated for $7 \mathrm{~d}$, and this reduction was transient, as the phosphorylation levels returned to approximately control levels by $30 \mathrm{~d}$; in contrast, the phosphorylation of neither Stat3 nor Erk $1 / 2$ was affected by BSSCE treatment (Fig. 5(C)). In the day 7 and day 15 groups, the hepatic non-haeme Fe concentrations were approximately $75 \%$ of those in the control diet-fed mice and increased slightly to $82 \%$ of those in the day 30 group (Fig. 5(D)). Splenic non-haeme Fe concentrations decreased steadily, reaching $65 \%$ of those in the control group by day 15 (Fig. 5(E)). Serum Fe concentrations increased significantly, reaching approximately $135 \%$ of the control levels in the day 7, 15 and 30 groups (Fig. 5(F)). Similarly, transferrin saturation in the treated groups increased steadily, reaching $132 \%$ of the control levels by day 30 (Fig. 5(G)). Furthermore, because Hamp1 expression decreased significantly in the BSSCE-fed mice, we also measured the mRNA levels of the Id1 (Fig. $5(\mathrm{H})$ ) and Bmp6 (Fig. 5(I)) genes (both of which have been reported to exhibit the same regulatory changes as Hamp1 in the liver ${ }^{(27)}$ ), and we found that the BSSCE-fed mice had similar transient reductions in the expression of these two genes. We also measured several haematological parameters in the BSSCE-fed mice and found that their erythrocyte counts, $\mathrm{Hb}$ concentrations and haematocrit values were elevated relative to those in the control diet-fed mice (Table 2). 

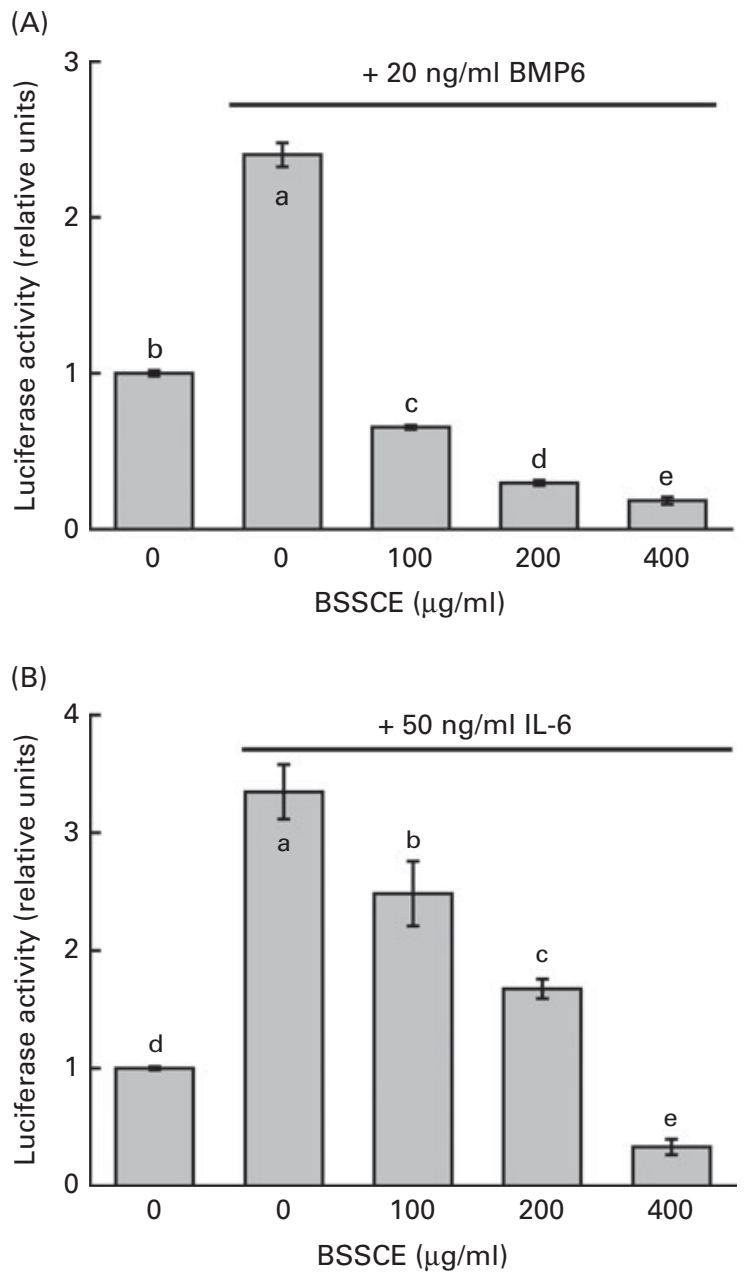

Fig. 4. Black soyabean seed coat extract (BSSCE) inhibits bone morphogenetic protein 6 (BMP6)- and IL-6-induced HAMP transcription measured using a luciferase promoter assay. HAMP promoter activity was measured as relative luciferase activity (calculated as the ratio of firefly:Renilla luciferase) in HEK293 cells transfected with a HAMP promoter-driven luciferase reporter. The cells were treated with BSSCE in the presence or absence of $20 \mathrm{ng} / \mathrm{ml}$ BMP6 (A) or $50 \mathrm{ng} / \mathrm{ml} \mathrm{IL-6} \mathrm{(B)} \mathrm{for} 24 \mathrm{~h}$. Data are means and standard deviations represented by vertical bars; $n 3$ replicates per group. $\mathrm{a}, \mathrm{b}, \mathrm{c}, \mathrm{d}, \mathrm{e}$ Mean values with unlike letters were significantly different $(P<0.05)$.

\section{Discussion}

Hepcidin, the major regulator of $\mathrm{Fe}$ homeostasis, binds to and induces the degradation of ferroportin, the only known cellular Fe exporter, thereby decreasing both Fe absorption from the duodenum and Fe release from the reticuloendothelial macrophages ${ }^{(2)}$. Therefore, controlling Fe absorption in the intestine by up-regulating the levels of ferroportin is a potentially feasible approach for boosting $\mathrm{Fe}$ concentrations to treat inflammatory anaemia, chronic inflammatory anaemia and Fe-deficiency anaemia. Recent studies ${ }^{(11,12,26)}$ have shown that an antagonist of IL- 6 ameliorates inflammatory anaemia; however, further studies are needed to test this compound's safety in clinical applications. Moreover, soluble haemojuvelin (HJV) and dorsomorphin (two inhibitors of BMP in the BMP/SMAD-targeting pathway) have promising curative effects in mouse models of chronic inflammation ${ }^{(8,10,11,13)}$. The use of hepcidin-targeted therapeutics is considered a breakthrough cure for Fe metabolic disorders and associated diseases ${ }^{(8,13,14)}$.

In China, many remedies are derived from daily dietary components $^{(15,17)}$. Indeed, many documented remedies are focused on curing anaemia and enhancing physical fitness, and these remedies include daily foods that are listed in the traditional Chinese pharmacopoeia ${ }^{(16)}$. However, whether these foods cure anaemia by regulating hepcidin expression has not been investigated previously. Therefore, we obtained extracts of several 'black foods', including G. max (black soyabean), A. auricula-judae (black fungus), S. indicum seeds (black sesame seeds) and D. lotus (date plum or persimmon, Hei Zao), and tested their effect on hepcidin expression. Of these four extracts, only the black soyabean coat extract significantly inhibited hepcidin expression, despite the relatively low total Fe concentration in this food. We, therefore, conclude that black soyabean coat extract probably regulates Fe metabolism by down-regulating hepcidin expression.

In Asia, black soyabeans are used medicinally for detoxification, reduction of inflammation and enhancement of blood components, and the safety and pharmacokinetics of black soyabeans have been investigated ${ }^{(28)}$. Studies have shown that polysaccharides in black soyabeans promote myelopoiesis and the reconstitution of bone marrow following myelopoiesis suppression by 5-fluorouracil treatment and/or irradiation $^{(29)}$, and recent research has focused on the antioxidant activity of anthocyanins, which are an abundant component of $\mathrm{BSSCE}^{(30)}$. Herein, we report for the first time that BSSCE inhibits hepcidin expression and thus its feasibility in treating hepcidin-associated diseases merits further analysis.

We also found that the phosphorylation levels of SMAD1/5/8 (a set of transcription factors that activate the HAMP gene) decreased in a dose- and time-dependent manner, whereas those of STAT3 and ERK1/2 were relatively unchanged in the BSSCE-treated cells. These data suggest that BSSCE might function by inhibiting the BMP/SMAD signalling pathway. Moreover, BSSCE treatment reduced the phosphorylation levels of SMAD1/5/8 but not of STAT3 in the context of IL-6 induction, which suggests that BSSCE inhibits IL-6-induced hepcidin expression primarily by inhibiting the SMAD pathway, but not the STAT pathway ${ }^{(31)}$.

Importantly, our in vitro results were supported by the results of in vivo experiments using mice that were fed a diet containing BSSCE. These mice exhibited reduced hepatic hepcidin expression, as well as reduced expression of both the $I d 1$ and $B m p 6$ genes, both of which have been reported to exhibit the same regulatory changes as Hamp1 in the liver ${ }^{(27)}$. Consistent with our in vitro results, BSSCE also reduced the phosphorylation levels of Smad1/5/8 in vivo. At the physiological level, the BSSCE-fed mice had reduced Fe concentrations in the spleen and elevated Fe concentrations in the serum, which would be expected based on the biological actions of hepcidin, perhaps due to decreased hepcidin expression and increased Fe mobilisation. However, hepatic Fe content was decreased, which was somewhat unexpected, given that a hallmark of hepcidin-knockout mice is increased hepatic Fe concentration ${ }^{(32)}$. Because hepatic Fe accumulates 
(A)
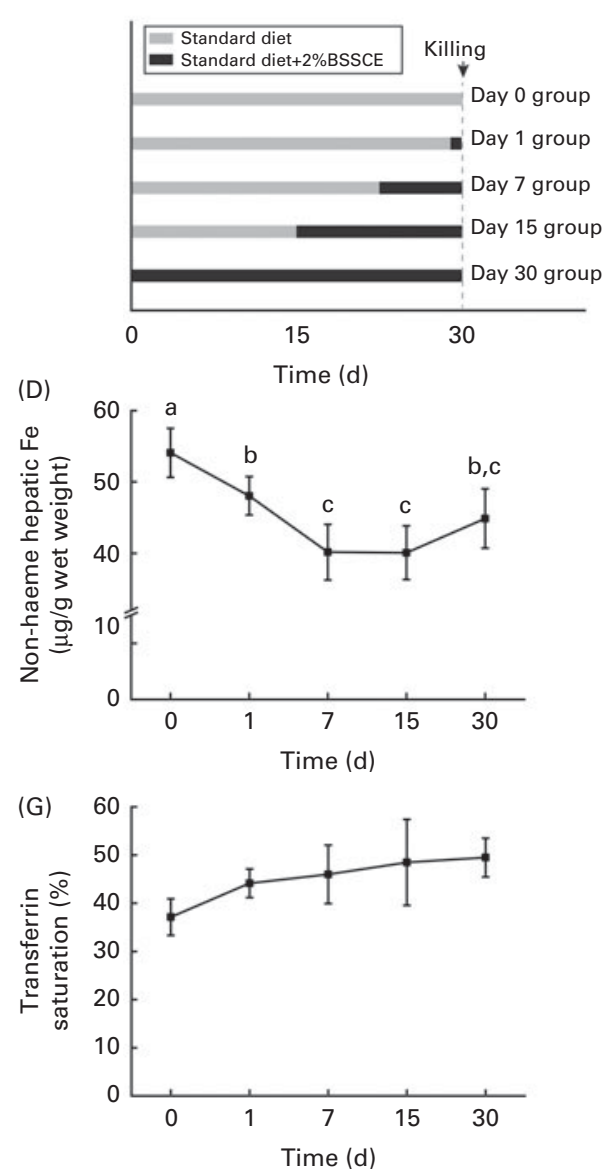

(B)

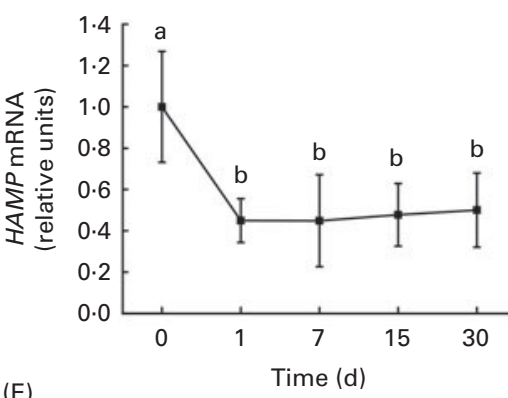

(E)
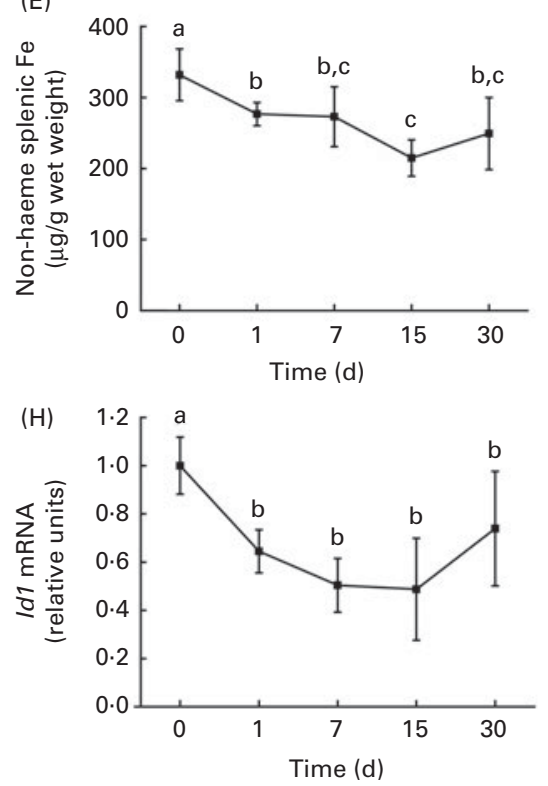

(C) pStat3

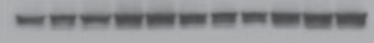

Stat3

pSmad1/5/8

Smad1

pErk1/2

Erk1/2

$\beta$-Actin
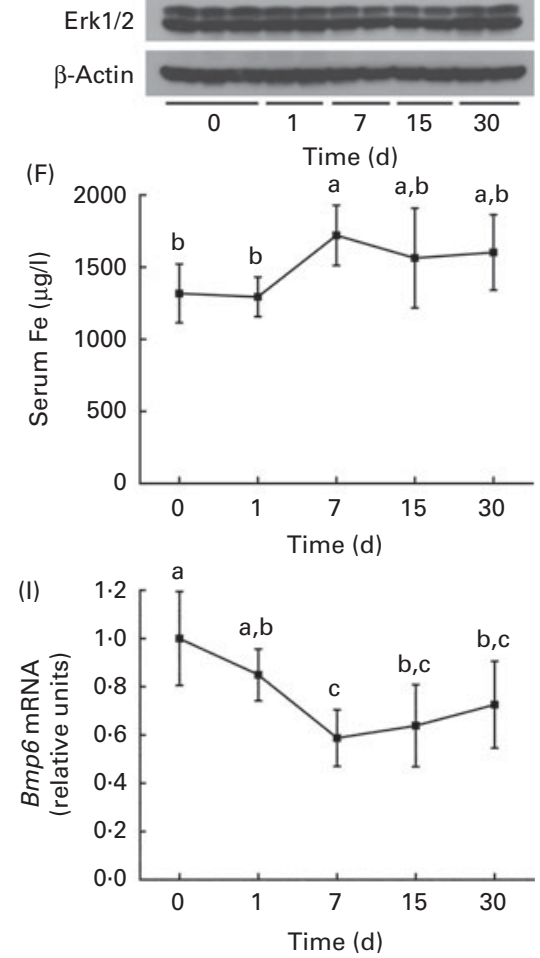

Fig. 5. Black soyabean seed coat extract (BSSCE) inhibits hepcidin expression in vivo and increases iron mobilisation in mice. (A) Male C57BL/6 mice were fed a standard diet $(\square)$ containing $2.0 \%$ BSSCE $(\square)$ for $0,1,7,15$ or $30 \mathrm{~d}$, after which they were killed for biochemical and physiological analyses. (B) Hamp1 expression normalised to Actb ( $\beta$-actin) expression. (C) Western blot analysis of phosphorylated mothers against decapentaplegic homolog protein $1 / 5 / 8$ (pSmad1/5/8), phosphorylated signal transducer and activator of transcription 3 (pStat3) and phosphorylated extracellular signal-regulated kinase 1/2 (pErk1/2) levels. $\beta$-Actin was used as a loading control. ( $d$-i) Mobilised hepatic iron concentrations $(D)$, non-haeme splenic iron concentrations $(E)$, serum iron concentrations $(F)$, serum transferrin saturation $(G)$, and the expression levels of hepatic inhibitor of DNA binding $1($ Id1) $(H)$ and bone morphogenetic protein $6(B m p 6)$ (I) were measured in mice that were treated with BSSCE for the indicated number of days. The summary data in (B) and (D) $-(\mathrm{I})$ are presented as means and standard deviations represented by vertical bars; $n$ 6-8 mice/group. ${ }^{\mathrm{a}, \mathrm{b}, \mathrm{c}}$ Mean values with unlike letters were significantly different $(P<0 \cdot 05)$.

over a long period of time in the hepcidin-knockout mice, we speculated that the reduced hepatic Fe concentrations in the BSSCE-fed mice might be caused by the relatively short treatment time and the mobilisation of hepatic Fe is a result of inhibited hepatic hepcidin expression in the early stages.
Starting on the 15th day of BSSCE treatment, hepatic Fe concentrations increased, further supporting this hypothesis. Moreover, a recent report has shown that the Chinese medicinal herb Caulis Spatholobi (a novel hepcidin inhibitor) has a similar effect on hepatic Fe concentrations ${ }^{(9)}$. Finally, the

Table 2. Effect of dietary black soyabean seed coat extract (BSSCE) on haematopoietic function in mice (Mean values and standard deviations, $n 6-8$ mice/group)

\begin{tabular}{|c|c|c|c|c|c|c|c|c|c|c|}
\hline & \multicolumn{10}{|c|}{ Groups of mice fed a diet containing $2 \%$ BSSCE for the indicated number of days } \\
\hline & \multicolumn{2}{|c|}{ Day 0} & \multicolumn{2}{|c|}{ Day 1} & \multicolumn{2}{|c|}{ Day 7} & \multicolumn{2}{|c|}{ Day 15} & \multicolumn{2}{|c|}{ Day 30} \\
\hline & Mean & SD & Mean & SD & Mean & SD & Mean & SD & Mean & SD \\
\hline $\operatorname{RBC}\left(10^{6} / \mu \mathrm{l}\right)$ & $8.92^{a}$ & 0.21 & $8.91^{a}$ & 0.29 & $9.51^{\mathrm{b}}$ & 0.27 & $9.77^{\mathrm{b}}$ & 0.36 & $9.87^{\mathrm{b}}$ & 0.56 \\
\hline $\mathrm{Hb}(\mathrm{g} / \mathrm{l})$ & $133 \cdot 17^{\mathrm{a}}$ & $2 \cdot 23$ & $136 \cdot 01^{\mathrm{a}}$ & $2 \cdot 83$ & $144.83^{\mathrm{b}}$ & 1.72 & $144.83^{\mathrm{b}}$ & 3.76 & $145 \cdot 51^{\mathrm{b}}$ & $2 \cdot 74$ \\
\hline HCT (\%) & $41 \cdot 32^{\mathrm{a}}$ & 0.97 & $42 \cdot 33^{a}$ & $1 \cdot 16$ & $44 \cdot 2^{\mathrm{b}}$ & $1 \cdot 21$ & $44.38^{\mathrm{b}}$ & 1.26 & $44 \cdot 74^{b}$ & 0.88 \\
\hline MCV (fl) & $46 \cdot 14$ & 0.46 & $46 \cdot 73$ & 0.78 & 46.69 & 0.41 & $45 \cdot 83$ & 0.4 & $46 \cdot 19$ & 0.93 \\
\hline
\end{tabular}

RBC, erythrocytes; HCT, haematocrit; MCV, mean corpuscular volume.

${ }^{\mathrm{a}, \mathrm{b}}$ Mean values with unlike superscript letters were significantly different $(P<0.05)$. 
BSSCE-fed mice exhibited large increases in their erythrocyte counts, Hb concentrations and haematocrit values. These experiments suggest that BSSCE regulates Fe metabolism by inhibiting the expression of hepcidin, thereby boosting haematopoiesis.

In previous studies ${ }^{(10,19)}$, the hepcidin antagonists dorsomorphin and LDN193189 have been found to cause adverse side effects due to their chemical structures. Based on our findings, it can be suggested that BSSCE may be a suitable substitute for these antagonists. In China, black soyabeans have been grown for several centuries and are an important daily food staple in the Chinese diet. Black soyabeans also play a functional role in traditional Chinese medicine dating back to ancient China.

In conclusion, the present results suggest that black soyabeans can be used as a daily dietary supplement and as a potential therapeutic agent to improve the Fe status in patients with anaemia of chronic disease or Fe-deficiency anaemia. Future studies should attempt to identify the precise components in BSSCE that regulate hepcidin expression and mediate these positive therapeutic effects.

\section{Acknowledgements}

The authors are grateful to Dr Pauline Lee and Dr Jaroslav Truksa (The Scripps Research Institute, La Jolla, CA, USA) for generously providing the HAMP promoter plasmid. They are also grateful to the members of the Wang Laboratory for their encouragement and helpful comments.

The present study was supported by research grants from the Chinese Ministry of Science and Technology (numbers 2011CB966200 and 2012BAD33B05 to F. W.) and Chinese National Natural Science Foundation grants (numbers 31225013, 31330036 and 31030039 to F. W.) and also by the Distinguished Professorship Program from Zhejiang University (to F. W.).

The authors' contributions are as follows: M. M. and F. W. designed the research; M. M., A. W., P. A., X. D., Q. W. and X. S. carried out the experiments; M. M. and F. W. wrote the paper.

None of the authors has a conflict of interest to declare.

\section{References}

1. Andrews NC \& Schmidt PJ (2007) Iron homeostasis. Ann Rev Physiol 69, 69-85.

2. Nemeth E, Tuttle MS, Powelson J, et al. (2004) Hepcidin regulates cellular iron efflux by binding to ferroportin and inducing its internalization. Science 306, 2090-2093.

3. Zhang Z, Zhang F, An P, et al. (2011) Ferroportin1 deficiency in mouse macrophages impairs iron homeostasis and inflammatory responses. Blood 118, 1912-1922.

4. Ganz T \& Nemeth E (2012) Hepcidin and iron homeostasis. Biochim Biophys Acta 1823, 1434-1443.

5. Ganz T (2011) Hepcidin and iron regulation, 10 years later. Blood 117, 4425-4433.

6. Hentze MW, Muckenthaler MU, Galy B, et al. (2010) Two to tango: regulation of mammalian iron metabolism. Cell $\mathbf{1 4 2}$, $24-38$.
7. Pinto JP, Ribeiro S, Pontes H, et al. (2008) Erythropoietin mediates hepcidin expression in hepatocytes through EPOR signaling and regulation of C/EBPalpha. Blood 111, 5727-5733.

8. Sun CC, Vaja V, Babitt JL, et al. (2012) Targeting the hepcidin-ferroportin axis to develop new treatment strategies for anemia of chronic disease and anemia of inflammation. Am J Hematol 87, 392-400.

9. Guan Y, An P, Zhang Z, et al. (2013) Screening identifies the Chinese medicinal plant Caulis Spatholobi as an effective HAMP expression inhibitor. $J$ Nutr.

10. Yu PB, Hong CC, Sachidanandan C, et al. (2008) Dorsomorphin inhibits BMP signals required for embryogenesis and iron metabolism. Nat Chem Biol 4, 33-41.

11. Theurl I, Schroll A, Sonnweber T, et al. (2011) Pharmacologic inhibition of hepcidin expression reverses anemia of chronic inflammation in rats. Blood 118, 4977-4984.

12. Song SN, Tomosugi N, Kawabata H, et al. (2010) Downregulation of hepcidin resulting from long-term treatment with an anti-IL-6 receptor antibody (tocilizumab) improves anemia of inflammation in multicentric Castleman disease. Blood 116, 3627-3634.

13. Wang L, Trebicka E, Fu Y, et al. (2012) The bone morphogenetic protein-hepcidin axis as a therapeutic target in inflammatory bowel disease. Inflamm Bowel Dis 18, $112-119$.

14. Fung E, Sugianto P, Hsu J, et al. (2013) High-throughput screening of small molecules identifies hepcidin antagonists. Mol Pharmacol 83, 681-690.

15. Li L-T, Yin L-J \& Saito M (2004) Function of traditional foods and food culture in China. Jpn Agric Res Quart 38, 213-220.

16. Koo LC (1984) The use of food to treat and prevent disease in Chinese culture. Soc Sci Med 18, 757-766.

17. Graziose R, Lila MA \& Raskin I (2010) Merging traditional Chinese medicine with modern drug discovery technologies to find novel drugs and functional foods. Curr Drug Discov Technol 7, 2-12.

18. Layrisse M, Cook J, Martinez C, et al. (1969) Food iron absorption: a comparison of vegetable and animal foods. Blood 33, 430-443.

19. Poli M, Girelli D, Campostrini N, et al. (2011) Heparin: a potent inhibitor of hepcidin expression in vitro and in vivo. Blood 117, 997-1004.

20. Steinbicker AU, Sachidanandan C, Vonner AJ, et al. (2011) Inhibition of bone morphogenetic protein signaling attenuates anemia associated with inflammation. Blood 117, 4915-4923.

21. Truksa J, Lee P \& Beutler E (2009) Two BMP responsive elements, STAT, and bZIP/HNF4/COUP motifs of the hepcidin promoter are critical for BMP, SMAD1, and HJV responsiveness. Blood 113, 688-695.

22. Pandur E, Sipos K, Grama L, et al. (2013) Prohepcidin binds to the HAMP promoter and autoregulates its own expression. Biochem J 451, 301-311.

23. American Institute of Nutrition (1977) Report of the American Institute of Nutrition ad boc Committee on Standards for Nutritional Studies. J Nutr 107, 1340-1348.

24. Sun L, Yu Y, Huang T, et al. (2012) Associations between ionomic profile and metabolic abnormalities in human population. PLOS ONE 7, e38845.

25. Andriopoulos B Jr, Coradini E, Xia Y, et al. (2009) BMP6 is a key endogenous regulator of hepcidin expression and iron metabolism. Nat Genet 41, 482-487. 
26. Nishimoto N \& Kishimoto T (2004) Inhibition of IL-6 for the treatment of inflammatory diseases. Curr Opin Pharmacol $\mathbf{4}$, 386-391.

27. Kautz L, Meynard D, Monnier A, et al. (2008) Iron regulates phosphorylation of Smad1/5/8 and gene expression of Bmp6, Smad 7, Id1, and Atoh8 in the mouse liver. Blood 112, 1503-1509.

28. Jeon S, Han S, Lee J, et al. (2012) The safety and pharmacokinetics of cyanidin-3-glucoside after 2-week administration of black bean seed coat extract in healthy subjects. Korean J Physiol Pharmacol 16, 249-253.

29. Liao H-F, Chen Y-J \& Yang Y-C (2005) A novel polysaccharide of black soybean promotes myelopoiesis and reconstitutes bone marrow after 5-flurouracil- and irradiation-induced myelosuppression. Life Sci 77, 400-413.
30. Liao H-F, Chou C-J, Wu S-H, et al. (2001) Isolation and characterization of an active compound from black soybean [Glycine $\max (\mathrm{L}$.) Merr.] and its effect on proliferation and differentiation of human leukemic U937 cells. Anticancer Drugs 12, 841-846.

31. Besson-Fournier C, Latour C, Kautz L, et al. (2012) Induction of activin $\mathrm{B}$ by inflamm atory stimuli up-regulates expression of the iron-regulatory peptide hepcidin through Smad1/5/8 signaling. Blood 120, 431-439.

32. Nicolas G, Bennoun M, Devaux I, et al. (2001) Lack of hepcidin gene expression and severe tissue iron overload in upstream stimulatory factor 2 (USF2) knockout mice. Proc Natl Acad Sci 98, 8780-8785. 